\title{
REACH SCALE APPLICATION OF UAV+SFM METHOD IN SHALLOW RIVERS HYPERSPATIAL BATHYMETRY
}

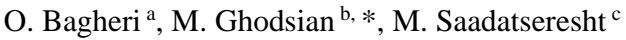 \\ a Faculty of Civil and Environmental Engineering, Tarbiat Modares University, Tehran, Iran - omid.bagheri@ modares.ac.ir \\ ${ }^{b}$ Faculty of Civil and Environmental Engineering and Water Engineering Research Institute, Tarbiat Modares University, Tehran, \\ Iran-ghods@modares.ac.ir \\ ${ }^{c}$ School of Surveying and Geomatics Engineering, College of Eng., University of Tehran, Tehran, Iran - msaadat@ut.ac.ir
}

\author{
Commission VI, WG VI/4
}

KEY WORDS: UAV, SfM, Alarm River, Hyperspatial Resolution, Near-Census River Science, Shallow Rivers Bathymetry

\begin{abstract}
:
Nowadays, rivers are impacted by different human activities and highly regulated. To rehabilitate these systems, spatial and processbased analyses of rivers are essential. Hydrodynamic models are sophisticated tools in this regard and instream topography is one of the most important input of these models. To represent hyperspatial topography and bathymetry in shallow rivers, UAV imagery and structure from motion may be an optimum method considering the extent of application, vegetation condition and flow quality. However, at the present there is no available workflow for applications of UAV+SfM method in riverine environments at extent of reach or higher scales. Therefore, in this study a new workflow has been presented and evaluated in Alarm River. The evaluation showed that the workflow provides $2 \mathrm{~m} / \mathrm{s}$ speed for UAV while mapping flight lines with low illumination changes. Specific pattern of image acquisition in the proposed workflow leads to substantial decrease of process time. In addition, precise control of flight height and overlap of images may lead to consistent accurate results. The result of validation against rtkGNSS data points showed that the suggested workflow is capable of providing $0.01 \mathrm{~m}$-resolution topographic data with an error less than $0.075 \mathrm{~m}$ and $95 \%$ level of confidence in clear shallow rivers.
\end{abstract}

\section{INTRODUCTION}

Nowadays, many rivers across the world are highly regulated and changed either in flow or sediment regimes (Brown and Pasternack, 2008). Rehabilitation of these rivers is an increasing demand and needs sophisticated tools to assess the current condition of the river. The regulated river can be reengineered and rehabilitated using influencing parameters derived from the assessment. Such parameters are used in most approaches like SHIRA for spawning habitat rehabilitation (Wheaton et al., 2004a, Wheaton et al., 2004b). Hydrodynamic models are strong tools in process-based and ecohydraulics analyses of rivers which have been widely used in this realm and shown convincing results. The most important input of these models is the river bathymetry (Pasternack, 2011).

Previously, due to lack of surveying technology, scientists tried to overcome the limitations in data collecting by using simplifying approaches. For instance, cross-sectional approach or reference reaches have been used, but these approaches failed to represent the real processes of river even in simple river systems. Their failure can be due to interpolation error among far apart crosssections or inaccurate approaches for extrapolating the result in reference reaches (Pasternack, 2011). In order to use spatially explicit approaches like near-census or hyperspatial instead of aforementioned simplifying approaches, new surveying methods or modified current methods can be presented. In order to enhance the validity of such simplifying approaches to develop to spatially explicit approaches like nearcensus or hyperspatial, new surveying methods may be presented or the present methods may be improved.
Using a single technique to provide such data is not applicable (unless in limited parts of the system) due to complexity of river systems in all aspects such as shape, vegetation coverage, and hydraulics condition (Bangen et al., 2014).

Of note, low accuracy and coarse spatial and temporal resolution of satellite sensors hinder the use of field surveying and developing close range methods in topographic data acquisition of shallow rivers.

Ground-based surveying methods (total station, GNSS and TLS) are incapable of efficiently providing high resolution topographic data over reach scale despite of representing golden standard in accuracy (Bangen et al., 2014). In addition, sonar methods only can be applied in deep enough submerged regions. These reasons caused vast growth of aerial methods. However, high cost, coarse resolution and other limitations of bathymetric LiDaR and in contrast, fast developments of UAVs and image processing packages that use structure from motion technique as a solution, caused fast growth of photogrammetric methods (Woodget et al., 2015).

Few studies have shown that it is feasible to use multi-viewed images of riverine environments by low attitude aerial systems and SfM photogrammetry to produce high resolution bathymetry data at the mesoscale $(10 \mathrm{~m}$ to a few hundred meters) with a convincing error range (Woodget et al. 2015). However, in rehabilitation scenarios we are dealing with scales from reach $\left(10^{2}-10^{3}\right.$ channel widths) to segment $\left(10^{3}-10^{4}\right.$ channel widths) (Pasternack, 2011). In such scenarios, use of aforementioned photogrammetric methods are not feasible.

Therefore, the aim of this study is to introduce and evaluate a workflow for application of UAV+SfM method in collecting

\footnotetext{
* Corresponding author
} 
hyperspatial resolution topographic and bathymetric data in shallow rivers with short-spare vegetation coverage.

\section{STUDY SITE}

Alarm River (Lar National Park, Iran) has been selected for evaluation of the suggested method because it has a diverse hydrological, morphological and vegetation condition in a relatively small length of the river (figure 1). It is a mountainous-meandering river with cobble-gravel substrate and average slope of 7 percent. Its average width is from 3 to 5 meters and the average depth is from 0.2 to 0.5 meter. Alarm River is usually clear and only gets muddy due to snow melting in springs. There is a short spare vegetation coverage at the upstream and relatively a long dense one at the downstream. Alarm River is also one of unique habitats of Salmo trutta and a research site for this fish as well (Bagheri, 2015).

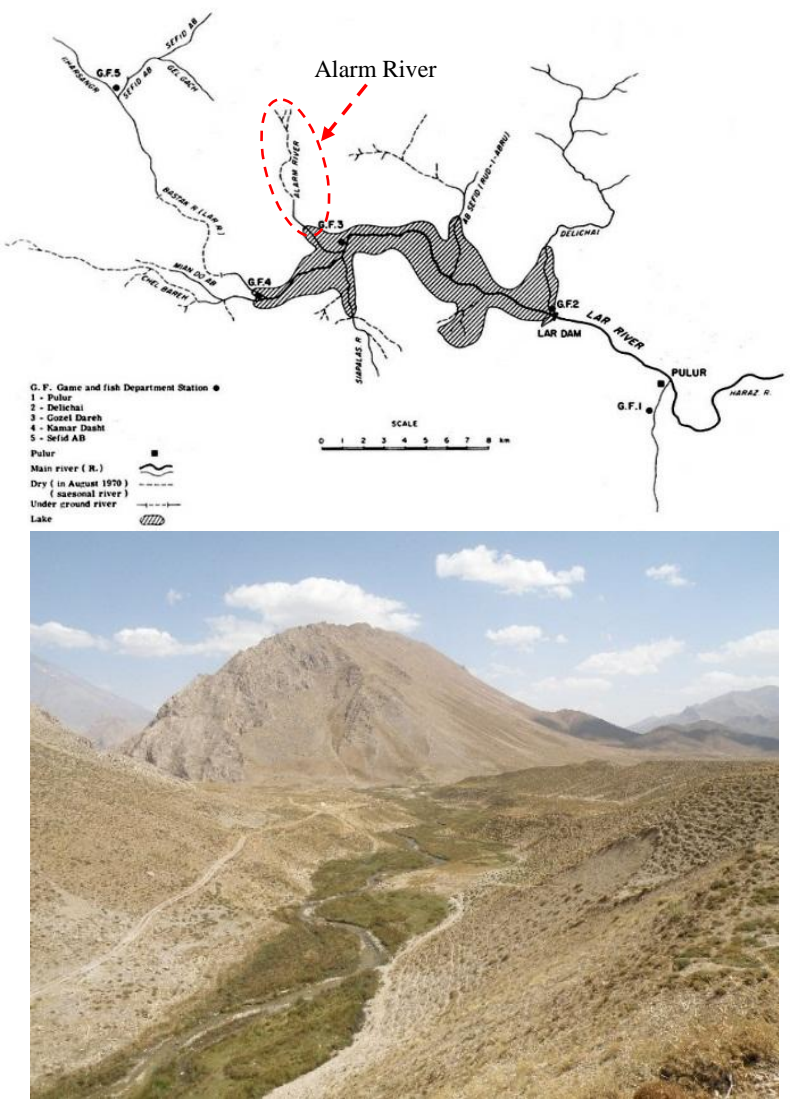

Figure 1. Alarm River, Lar National Park - downstream view

\section{DATA COLLECTION}

In this study, S1000 multirotor and Canon 5D MarkIII was used for image acquisition (Figure 2) and Agisoft PhotoScan Pro® was used for SfM processing. Flight has been implemented in $32 \mathrm{~m}$ height over a flight line to have one centimeter resolution images with over $80 \%$ overlap based on calibration results. The flight line was characterized by waypoints at appropriate intervals to consider plan and elevation changes in flight. The proposed flight design made $3 \mathrm{D}$ navigation of UAV feasible and leads to precise control on flight height, and as a result, image resolution was constant all over the scene. This leads to constant point cloud density and DEM resolution as well.

Due to lack of any criteria on the optimum number of GCPs to obtain high accuracy results, we consider 680 GCPs along 1400 meters of the Alarm River. The markers of artificial ground control points were made from pieces of carpet as shown in figure 3 .

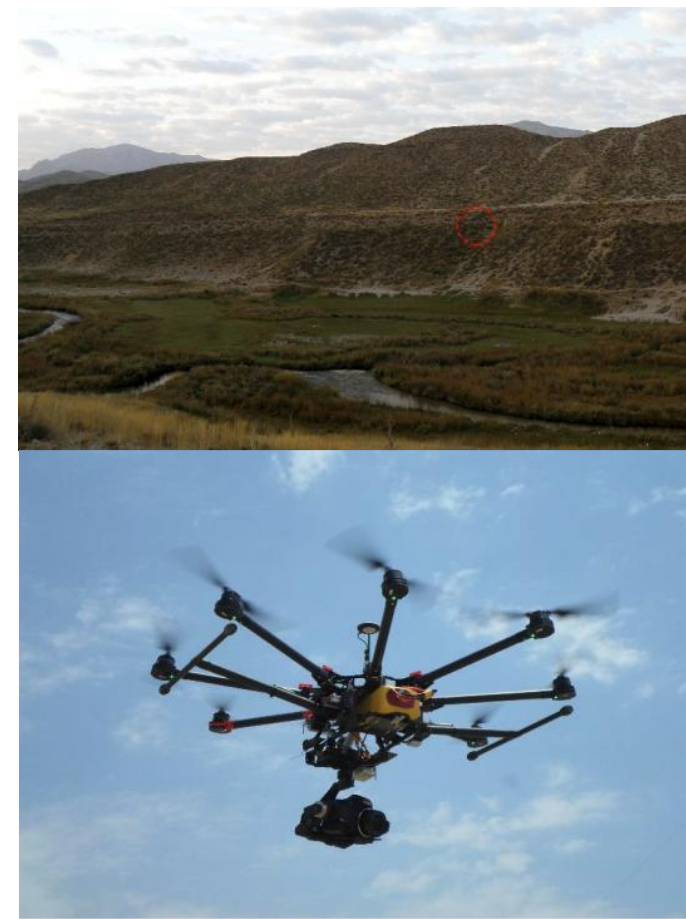

Figure 2. S1000 multirotor with Canon 5D MarkIII

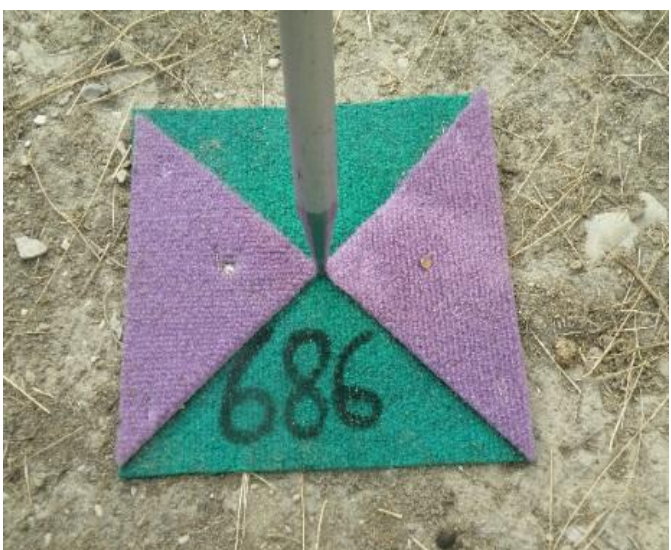

Figure 3. Artificial Ground Control Points Marker

Prior to image acquisition, GCPs were randomly and uniformly distributed across the river site to sample a large range of interest elevations. These markers were distributed on both banks and in the main channel where it was possible (on side and middle bars, boulders, etc.). GCPs were surveyed using rtkGNSS method by JAVAD GNSS triumph-1.

To use refraction correction algorithms, water surface model should be constructed. It can be created by extracting water edges from resulted orthophoto and DEM at the end of SfM process in an appropriate interval and using a TIN model to build DEM of estimated water surface elevation. In cases which there are parts such as undercuts or overhanging vegetation, these edges are not visible in the orthophoto, accordingly some points with water depth should be collected for further modelling of the water surface elevation.

To validate the accuracy of UAV+SfM method, about 9450 rtkGNSS points were collected in both exposed and submerged regions by recoding flow depths where it was possible. Spatial 
distribution of validation and ground control points are shown in figure 4.

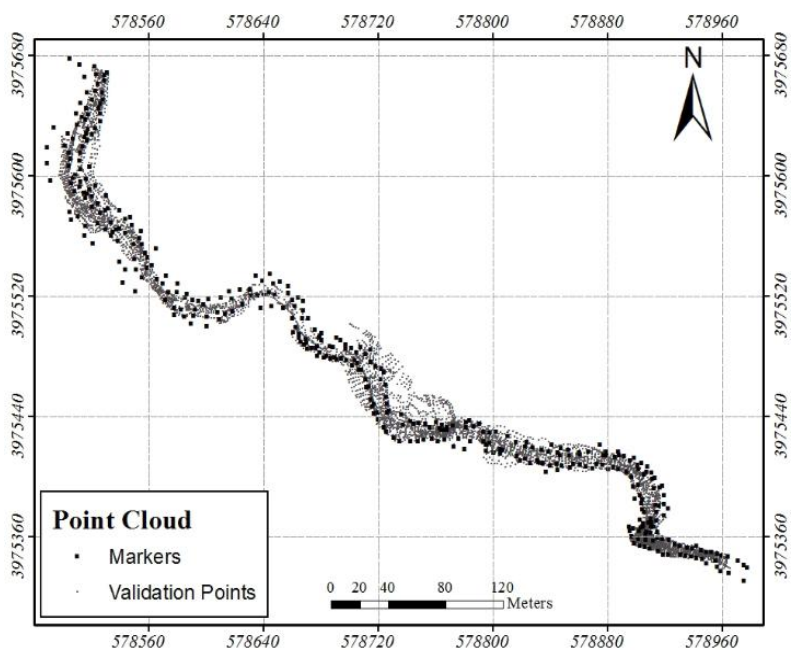

Figure 4. Spatial distribution of validation and ground control points

To map 1400 m of Alarm River, 945 images were taken during 11 minutes of flying by more than $80 \%$ overlap. Images were taken automatically by the speed of 2 frames per second. Camera image taking settings should be paid special attention due to having a significant effect on the process success. Shutter speed, f/stop and ISO should be carefully set in this regard.

\section{DATA PROCESSING}

Visual quality, viewing angle and flight elevation of the images should be evaluated before data processing and those which are inconsistent with specifications have to be eliminated. Poor visual quality images including those which are blurred usually occur due to UAV manoeuvring or vegetation motion. Although using IMU data, images far from nadir point (that have a bigger reflection) or out of allowable flight height $(\mathrm{H} \pm 1 \mathrm{~m})$ should be eliminated by considering aforementioned overlap condition. Most of these poor photos fail to affect the accuracy of final DEM, except the quality of the Orthophoto (Agisoft, 2015). However, SfM is capable of aligning slightly blurred photos from different viewing angle and flight height (different scales), but eliminating these photos will ensure the consistent hyperspatial resolution all over the topography. Equalization of IMU and GCPs coordinate systems is another step that may be considered in this stage.

Agisoft PhotoScan Pro® software packages were used to produce 3D models from still images. Algorithms like SIFT (Lowe, 2004) made this process feasible by matching conjugate points from overlapping images, estimating camera positions and then refining these positions and carrying out indirect georeferencing. By having precise camera locations and images, a dense point cloud was built (Agisoft, 2015). Generally, the SfM processing in PhotoScan is implemented by aligning photos, importing GCPs and camera locations optimisation, and building dense point cloud, mesh and texture. By the end of this process othrophoto and DEM can be exported.

The overestimation error in bed elevation of submerged areas due to refraction affect was estimated by a correction algorithm proposed by woodget et al. (2015). This correction is implemented by the equation (1). In this equation $\mathrm{E}_{\mathrm{RC}}$ is refraction corrected DEM elevation, Eo is the original DEM elevation and WSE is water surface elevation. 1.34 is refraction correction index in clear waters that alters less than $1 \%$ by salinity and temperature change (Woodget et al., 2015).

$E_{R C}=E_{O}-0.34 \times\left(E_{O}-W S E\right)$

Water surface model is constructed by extracting water edges from resulted orthophoto and DEM at the end of SfM process in an appropriate interval and using a TIN model to build DEM of estimated water surface elevation.

Accuracy of the method can be compared with gold standard accuracy methods like total station or rtkGNSS. To prevent making multiple stations due to lack of sight line in total station, we used the rtkGNSS method. The assessment was made for the original and corrected DEM by performing regression analysis and also calculating mean error and standard deviation of errors.

The aforementioned algorithm may be reliable for flow depths less than $0.7 \mathrm{~m}$ based on woodget et al. study (2015). The spectral-depth relationship method might be used to correct the refraction effect in submerged regions for flow depths from 0.7 $\mathrm{m}$ to $1 \mathrm{~m}$. However, more rtkGNSS and depth data points are required in this method and the results are site-specific and might be affected by scene illumination, flow and substrate condition as well (Lejot et al., 2007).

\section{RESULTS AND DISCUSSION}

The Orthophoto and Digital Elevation Model of the Alarm River are partially shown in figures 5 and 6. A summary of SfM process is given in table 1 . The markers accuracy data is given in table 2. In table 2, $\mathrm{X}, \mathrm{Y}$ and $\mathrm{Z}$ are longitude, latitude, and altitude respectively. The suggested workflow is capable of mapping flight lines by 2 meters per second and it could have been implement faster if sophisticated cameras had been used. Due to precise control of the flight height and image overlap, the DEM resolution is almost constant across the scene. However, fast implementation caused low illumination changes.

\begin{tabular}{|c|c|c|c|}
\hline Number of images & 939 & Tie points & $4,794,960$ \\
\hline Flying altitude $(\mathrm{m})$ & 32.2 & Projections & $10,834,346$ \\
\hline $\begin{array}{c}\text { Ground resolution } \\
(\mathrm{mm} / \text { pix })\end{array}$ & 7.61 & $\begin{array}{c}\text { Reprojection } \\
\text { error (pix) }\end{array}$ & 0.101 \\
\hline $\begin{array}{c}\text { Coverage area } \\
\left(\mathrm{m}^{2}\right)\end{array}$ & 64,200 & $\begin{array}{c}\text { Image } \\
\text { resolution }\end{array}$ & $5760 \times 3840$ \\
\hline $\begin{array}{c}\text { Number of } \\
\text { markers }\end{array}$ & 650 & Focal length & $24 \mathrm{~mm}$ \\
\hline Effective Overlap & 4.54 & $\begin{array}{c}\text { Pixel size } \\
\text { (um) }\end{array}$ & $6.44 \times 6.44$ \\
\hline Precalibrated & NO & \multicolumn{1}{|l}{} \\
\hline
\end{tabular}

Table 1. Processing Summary

\begin{tabular}{lccc}
\hline Direction & $\mathrm{X}$ & $\mathrm{Y}$ & $\mathrm{Z}$ \\
Mean $(\mathrm{m})$ & $-1.41 \mathrm{E}-05$ & $7.36 \mathrm{E}-05$ & $-1.19 \mathrm{E}-05$ \\
Standard Deviation $(\mathrm{m})$ & $7.13 \mathrm{E}-03$ & $9.00 \mathrm{E}-03$ & $7.37 \mathrm{E}-03$ \\
\hline
\end{tabular}

Table 2. Residual Errors associated with the georeferencing 
The visual quality assessment of orthophoto and DEM is satisfying and observed errors in elevation of submerged regions vary between -0.086 and $0.127 \mathrm{~m}$, with the mean error approximately equal to $0.007 \mathrm{~m}$ and the standard deviation equal to $0.041 \mathrm{~m}$. The elevation errors more than $0.05 \mathrm{~m}$ have usually been observed near the banks or over parts of the river bed that where covered by vegetation, woody debris, algae, mud, etc. In addition the flow condition can cause high elevation errors due to air entrainment, hydraulic jumps, etc. The plot of measured water depth against refraction corrected DEM is shown in figure 7 . Overhanging vegetation in small rivers may lead to underestimation of flow area, depending on channel and flow condition. The correction due to overhanging vegetation was considered manually. Meanwhile, several limitations for temporal resolution of the developed method due to the flow, vegetation and wind condition were also considered.

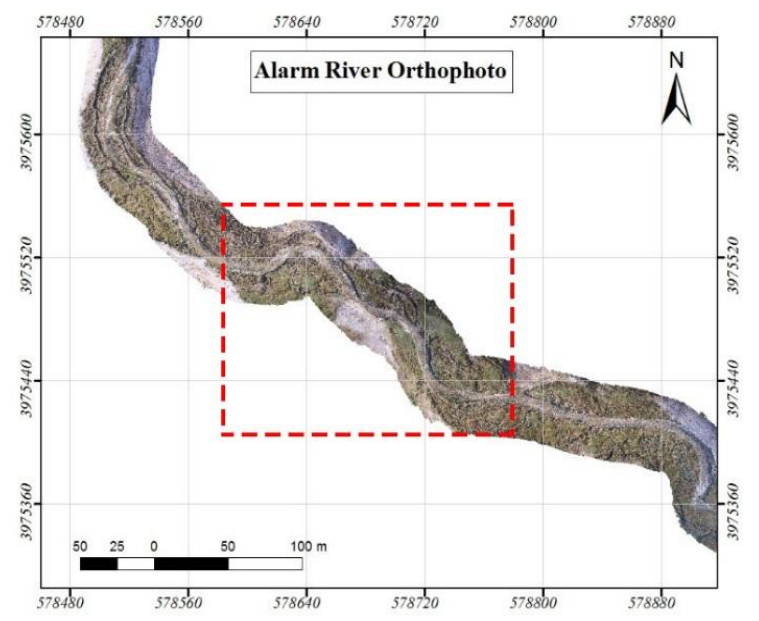

Figure 5. Part of the Alarm River Orthophoto

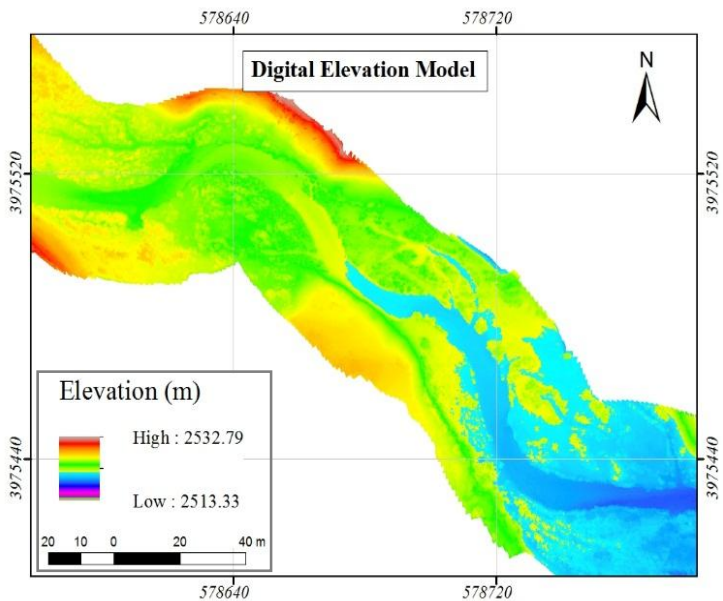

Figure 6. DEM of the red dashed rectangle as shown in figure 5

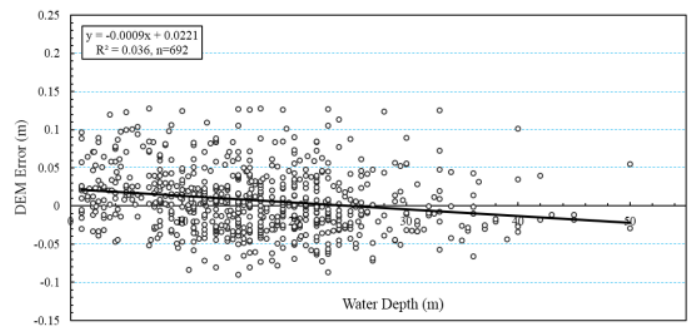

Figure 7. DEM error values against water depths

\section{CONCLUSION}

According to the result of this study, the suggested workflow for implementation of $\mathrm{UAV}+\mathrm{SfM}$ technique provides hyperspatial resolution data over reach to segment scales in shallow rivers with short-spare vegetation considering the temporal resolution limitations. Based on our assessment the suggested workflow is capable of providing DEMs by $0.01 \mathrm{~m}$ resolution, and with $95 \%$ confident interval the error will be less than $0.075 \mathrm{~m}$ in depths less than $0.5 \mathrm{~m}$ providing that the water is clear. In spite of providing hyperspatial resolution, application of the aforementioned method in smaller scales leads to logistical challenges that may not be economical as compared to rtkGNSS.

An appropriate flight plan by autopilot leads to a more effective control on flight height and precise control on photos coverage and overlap. The suggested workflow made $2 \mathrm{~m} / \mathrm{s}$ flying speed feasible, therefore reach scale applications of UAV+SfM were available. In addition, the results were improved by having more control over image-taking parameters. Furthermore, because of faster implementation, low illumination changes were observed that provided suitable and more effective conditions to use spectral-depth relationship method in refraction correction.

\section{ACKNOWLEDGEMENTS}

This study was carried out as part of a Tarbiat Moderes university funded MSc studentship for spawning habitat rehabilitation in Lar River. The cooperation of faculty of Civil and Environmental Engineering of Tarbiat Modares University in providing the fund is highly appreciated. We like to thank the Environmental Protection Agency of Tehran, especially Amir Abas Mashhadi Ahmadi. We also thank Fateh Aseman Sharif Corp. for providing the UAV and Camera, especially to Majid Dehghan. The field work assistance of Mohammad Hassan Badizad, Kamran Taheri and Ali Ali is also acknowledged. We like to thank Dr. Asghar Abdoli and Dr. Amy Woodget for their insightful guides.

\section{REFERENCES}

Agisoft, L. (2015). "AgiSoft PhotoScan User Manual." Professional Edition, Version 1.1. 6.

Bagheri, O. (2015). Construction of suitability curves and introduction of a new mapping method for Lar River rehabilitation, M.S. Thesis. Tarbiat Modares University, Tehran, Iran, pp. 120.

Bangen, S. G., et al. (2014). "A methodological intercomparison of topographic survey techniques for characterizing wadeable streams and rivers." Geomorphology, 206: $343-361$

Brown, R. A. and G. B. Pasternack (2008). "Engineered channel controls limiting spawning habitat rehabilitation success on regulated gravel-bed rivers." Geomorphology, 97(3): 631-654.

Lejot, J., et al. (2007). "Very high spatial resolution imagery for channel bathymetry and topography from an unmanned mapping controlled platform." Earth Surface Processes and Landforms, 32(11): 1705-1725. 
Lowe, D. G. (2004). "Distinctive image features from scaleinvariant keypoints." International journal of computer vision, 60(2): 91-110.

Pasternack, G. B. (2011). 2D modeling and ecohydraulic analysis, University of California at Davis.

Wheaton, J. M., et al. (2004a). "Spawning habitat rehabilitation-I. Conceptual approach and methods." International Journal of River Basin Management, 2(1): 3-20.

Wheaton, J. M., et al. (2004b). "Spawning habitat rehabilitation-II. Using hypothesis development and testing in design, Mokelumne river, California, USA." International Journal of River Basin Management, 2(1): 21-37.

Woodget, A., et al. (2015). "Quantifying submerged fluvial topography using hyperspatial resolution UAS imagery and structure from motion photogrammetry." Earth Surface Processes and Landforms, 40(1): 47-64. 